\title{
Symposium review: Multiple-trait single-step genomic evaluation for hoof health*
}

\author{
F. Malchiodi, ${ }^{1,2} \dagger \odot$ J. Jamrozik, ${ }^{2,3} \odot$ A.-M. Christen, ${ }^{4}$ A. Fleming, ${ }^{3} \odot$ G. J. Kistemaker, ${ }^{3}$ C. Richardson, ${ }^{5}$ \\ V. Daniel, ${ }^{6}$ D. F. Kelton, ${ }^{7}$ (D) F. S. Schenkel, ${ }^{2}$ (D) and F. Miglior ${ }^{2}$ (D) \\ ${ }^{1}$ Semex Alliance, Guelph, ON, N1H 6J2, Canada \\ ${ }^{2}$ Centre for Genetic Improvement of Livestock, Department of Animal Biosciences, University of Guelph, Guelph, ON, N1G 1Y2, Canada \\ ${ }^{3}$ Lactanet Canada, Guelph, ON N1K 1E5, Canada \\ ${ }^{4}$ Lactanet Canada, Sainte-Anne-de-Bellevue, QC H9X 3R4, Canada \\ ${ }^{5}$ School of Applied Systems Biology, La Trobe University, Bundoora, Victoria 3086, Australia \\ ${ }^{6}$ Vic's Custom Clips, Arva, ON NOM 1C0, Canada \\ ${ }^{7}$ Department of Population Medicine, Ontario Veterinary College, University of Guelph, Guelph, ON N1G 1Y2, Canada
}

\begin{abstract}
Hoof lesions represent an important issue in modern dairy herds, with reported prevalence in different countries ranging from 40 to $70 \%$. This high prevalence of hoof lesions has both economic and social consequences, resulting in increased labor expenses and decreasing animal production, longevity, reproduction, health, and welfare. Therefore, a key goal of dairy herds is to reduce the incidence of hoof lesions, which can be achieved both by improving management practices and through genetic selection. The Canadian dairy industry has recently released a hoof health sub-index. This national genetic evaluation program for hoof health was achieved by creating a centralized data collection system that routinely transfers data recorded by hoof trimmers into a coherent and sustainable national database. The 8 most prevalent lesions (digital dermatitis, interdigital dermatitis, interdigital hyperplasia, heel horn erosion, sole hemorrhage, sole ulcer, toe ulcer, and white line lesion) in Canada are analyzed with a multiple-trait model using a single-step genomic BLUP method. Estimated genomic breeding values for each lesion are combined into a sub-index according to their economic value and prevalence. In addition, data recorded within this system were used to create an interactive management report for dairy producers by Canadian DHI, including the prevalence of lesions
\end{abstract}

Received October 15, 2019.

Accepted January 17, 2020.

*Presented as part of the Joint ADSA/Interbull Session: Breeding and Genetics Data Pipelines for Implementation of Genomic Evaluation of Novel Traits at the ADSA Annual Meeting, Cincinnati, Ohio, June 2019.

†Corresponding author: fmalchio@uoguelph.ca on farm, their trends over time, and benchmarks with provincial and national averages.

Key words: hoof lesions, single-step genomic evaluation, hoof trimmer

\section{INTRODUCTION}

Hoof-related problems represent a major concern for the dairy industry globally. In Europe and North America, 40 to $70 \%$ of cows are reported to have at least one type of hoof lesion (Manske et al., 2002; Buch et al., 2011; Chapinal et al., 2013). This high prevalence of hoof lesions has both economic and social consequences, resulting in increased labor expenses while decreasing animal production, longevity, reproduction, health, and welfare (Shearer and van Amstel, 2011; Guard, 2017). Although the prevalence of lameness can be reduced through improved management practices, selecting for animals that have genetically superior hoof health offers a long-term, permanent solution. A genetic selection program for reduced hoof lesions could be implemented by selecting for traits correlated with hoof health, such as feet and leg conformation traits. However, moderate to low genetic correlations between hoof lesions and feet and leg conformation traits have been reported in different countries (van der Linde et al., 2010; Chapinal et al., 2013; Ødegård et al., 2014). These low correlations indicated the need to seek new phenotypes, because direct selection for them could prove to be more effective. Access to cost-effective phenotypes, beyond milk recording and classification, changed the headway of genetic selection, allowing selection for new traits, such as those related to health and efficiency (Miglior et al., 2017). In the last few years, different countries (i.e., Canada, the Netherlands, Norway, and other Scandinavian countries) have introduced genetic evaluations for hoof health (Heringstad et al., 2018). In Canada, a sys- 
tem to collect hoof lesion data that uses standardized and reliable scores was developed within a 4 -yr project that began in 2014. The project aimed to use standardized claw lesion data collected by hoof trimmers and to initiate a routine data flow to end users for improving hoof health, at both the management and genetic levels. Project outputs included development of a new DHI management report and a new genomic evaluation on hoof health. In 2017, a genomic evaluation for digital dermatitis was released for the Holstein breed by the Canadian dairy industry (Malchiodi et al., 2018), followed by a genomic evaluation for all major hoof lesions in 2018. The DHI management report was released in 2018, which included the prevalence of lesions on farm, their trends over time, 2 management lists, and benchmarks with provincial and national averages. Here, we describe the current established strategy for genetic improvement of hoof health in Canadian dairy cattle.

\section{MATERIALS AND METHODS}

\section{Data Collection System and Pipeline}

Data were collected by hoof trimmers during routine visits to Canadian herds starting in 2009. The trimmers participating in the project were trained to use a computerized lesion recording system on a rugged touchscreen computer platform (Hoof Supervisor, Dresser, WI). The system is based on the lesion descriptions proposed by the International Lameness Committee, a global collaboration of researchers, veterinarians, academics, and hoof-trimming professionals (Egger-Danner et al., 2015). To facilitate the correct identification of lesions, the hoof trimmers were asked to participate in training sessions and provided with a lesion severity scoring guide containing example photos of each lesion created by Alberta hoof trimmers (Alberta dairy hoof health project, 2014). Although this recording system allowed for recording standardized data across all Canadian provinces, one of the major limitations was the time required for the trimmer to upload the data from the tablet to the DHI system. To simplify data exchange between the trimmers and the DHI dairy database, a new interface was developed by Lactanet Canada (the 2019 partnership between Canadian Dairy Network, Canwest DHI, and Valacta, providing genetic and DHI services across Canada). Once the trimmer decided to contribute to data collection system, the tablet exchanges the information from all client herds that agreed to share their hoof health data with the DHI dairy database.

\section{Definition of Traits}

The 8 lesions considered were digital dermatitis (DD), heel horn erosion (HHE), sole hemorrhage (SH), interdigital dermatitis (ID), interdigital hyperplasia $(\mathbf{I H})$, toe ulcer (TU), sole ulcer (SU), and white line lesion (WL). The frequencies of the lesions are expressed as a percent of total hoof lesions within the population (Table 1). Frequencies reported were based on data from cows presented to the hoof trimmers. Therefore, the prevalence of hoof lesions reported may be overestimated compared with the real prevalence in the Canadian dairy population. This is because the process by which a cow is presented to the hoof trimmer may not be completely random, and cows with hoof lesions are likely to be preferentially presented to hoof trimmers (Malchiodi et al., 2017). Additional lesions were recorded through Hoof Supervisor; however, only lesions with a frequency $>1 \%$ in the Canadian Holstein population were included in the genomic evaluation for hoof health. Information on health status (presence or absence of a given lesion) for all 8 lesions was considered a binary trait $(0,1)$, where 1 was assigned to the presence of a lesion. A categorical definition from 0 to 3 , according to the severity of the case, was also tested. However, variance components estimated using versus not using the severity scale produced very similar results, and correlations between breeding values ranged from 0.95 to 0.98 (data not shown).

Because data are collected directly during routine trimming visits, not all cows present in the herd during the trimming session are presented to the hoof trimmer. The preselection of cows for trimming is rarely random, leading to potential bias and, consequently, inaccuracies in the genetic evaluation. This preselection effect was investigated but it did not appear to have a sizeable effect on the genetic evaluation (Malchiodi et al., 2017). Based on these results, only cows with trimming data were considered in the analyses. To be included in the

Table 1. Prevalence of hoof lesions ${ }^{1}$

\begin{tabular}{lc}
\hline Hoof lesion & Frequency $(\%)$ \\
\hline Digital dermatitis & 16.9 \\
Sole ulcer & 8.5 \\
Sole hemorrhage & 7.4 \\
White line lesion & 4.7 \\
Heel horn erosion & 2.8 \\
Interdigital dermatitis & 2.6 \\
Interdigital hyperplasia & 2.2 \\
Toe ulcer & 1.3
\end{tabular}

${ }^{1}$ Only lesions with a frequency $>1 \%$ in the Canadian Holstein population were reported. 
analyses, the trimming session needed to be recorded in the first $500 \mathrm{~d}$ postpartum and at least 5 records per hoof-trimming session per herd were required. Based on the low repeatability of the lesions, all available hoof-trimming sessions were included in the analysis to maximize the accuracy of the evaluation. Contemporary groups consisted of all cows in the herd with trimming records at a given trimming session. Dates of trimming sessions were assigned such that 7 consecutive days were combined into one trimming date. If a cow had more than one trimming session available in a given lactation, all sessions were considered in the analyses. If a cow had more than one trimming event within $7 \mathrm{~d}$, however, only the first trimming event was included in the analysis.

Finally, other health-related traits (i.e., mastitis and metabolic diseases) in Canada are considered different traits when they occur in first and later lactating animals (Koeck et al., 2015; Jamrozik et al., 2016). However, because genetic correlations among lesions recorded in parity 1 and parities $\geq 2$ were high, ranging from 0.89 (for DD and TU) to 1 (for ID, SH, SU, and $\mathrm{WL}$ ), it was decided to consider lesions recorded in different parities as one trait.

\section{Model}

After editing, the data set used to estimate the variance components included 307,172 records from 127,729 cows and 387,124 animals in the pedigree. Consistent with the other genetic evaluation for health traits already available in the national system, the evaluation for hoof health was implemented using a linear model. Linear models are computationally more practical for the scale and scope of routine genetic evaluations. However, because threshold models are theoretically better to use when binary traits (i.e., presence or absence of a hoof lesion) are considered, both models were tested on a sub-data set (data recorded between 2009 and 2012 in Alberta, British Columbia, and Ontario). No relevant differences between sire rankings and heritability were found when data were analyzed using either a threshold or a linear model (Malchiodi et al., 2017). Variance components were estimated for each lesion using the following multi-trait liner animal model:

$$
\mathbf{y}=\mathbf{X b}+\mathbf{Z}_{1} \mathbf{a}+\mathbf{Z}_{2} \mathbf{p}+\mathbf{e}
$$

where $\mathbf{y}$ is a vector of observations for all traits, $\mathbf{b}$ is a vector of all fixed effects (herd-date of trimming, hoof trimmer, parity, and stage of lactation at trimming), $\mathbf{a}$ is a vector of animal additive genetic effects, $\mathbf{p}$ is a vector of permanent environmental effects, $\mathbf{e}$ is a vector of residuals, and $\mathbf{X}, \mathbf{Z}_{1}$, and $\mathbf{Z}_{2}$ are the respective incidence matrices. Additive genetic, permanent environmental, and residual effects were assumed independent within and across traits.

Bayesian methods via Gibbs sampling were used for fitting the model. Prior distributions were normal for all location parameters and inverted Wishart with minimal number of degrees of freedom for all dispersion parameters. The total length of the Gibbs chain was 225,000 . A burn-in period (25,000 iterations) was determined based on trace plots of selected covariance components. Estimates were calculated as posterior means of all samples after burn-in for the respective parameters. The parameters were model covariance components, ratios of variances (including heritability and repeatability), genetic, permanent environmental, residual, and phenotypic correlations among traits. Posterior standard deviations were calculated as a measure of uncertainty of estimated parameters.

\section{Genomic Evaluation of Hoof Health}

A multiple-trait single-step genomic evaluation was implemented at Lactanet Canada using MiX99 and related software (MiX99 Development Team, 2017). Results presented in this study refer to data extracted on August 2018. The final data set had 328,861 records from 134,211 cows (daughters of 8,575 sires), and with 345,127 animals in the 4 -generation pedigree. There were 20,876 genotyped animals in the pedigree, including 5,498 sires of cows with data and 7,716 cows with data, respectively. Animals were genotyped either with a 50K SNP panel or with a low-density panel and imputed to 50K using FImpute (Sargolzaei et al., 2014). The evaluation was performed using the same model specified above, with the exception of the additive relationship matrix $\mathbf{A}$, which was replaced with the genotype-enhanced relationship matrix $\mathbf{H}$.

The genomic EBV for each of the 8 lesions were then combined in an overall hoof health index according to their economic value and genomic EBV standard deviation (SD). To be consistent with the expression of other Canadian proofs, the overall Hoof Health index is re-expressed as relative breeding value $(\mathbf{R B V})$ with a mean of 100 and SD of 5 for the base population, where a higher value indicates better resistance to hoof lesions. The base population was defined as officially proven sires born in a recent 10-yr period (2004-2014). To have an official evaluation for hoof health, a sire is required to have daughters in a minimum of 5 herds and a reliability greater than $70 \%$ for DD. Descriptive statistics for the bulls passing these thresholds are reported in Table 2. 


\section{Calculating the Economic Value of Hoof Lesions}

The economic value of each hoof lesion was calculated by determining the cost of lesion treatment as well as the additional labor required during the period from lesion treatment until the animal no longer experienced clinical or subclinical symptoms, similar to Berry and Amer (2005) and Guard (2017). The values used in the current research (lesion-specific costs, treatment time, and recovery period) were provided by Canadian industry experts in hoof health (hoof trimmers, veterinarians, and producers) and represented the current market value for supplies and labor in Canada. The aggregate lesion-specific economic value was therefore calculated as follows:

$$
\begin{aligned}
& E V_{H L}= \\
& \left(5 \% \times \Sigma E V_{V}+5 \% \times \Sigma E V_{P}+90 \% \times \Sigma E V_{H}+\Sigma E V_{R}\right) \times W
\end{aligned}
$$

where $E V_{H L}$ is the economic value of the hoof lesion, $\Sigma E V_{V}$ is the sum of the costs of treatment by the veterinarian (veterinary call-out service fee, labor cost, and the cost of all treatment supplies), $\Sigma E V_{P}$ is the sum of the costs of on-farm treatment of the hoof lesion by the producer (the labor cost of treatment by the producer and the cost of all on-farm treatment supplies), $\Sigma E V_{H}$ is the sum of the costs of treatment of the hoof lesion by the hoof trimmer (all treatment supplies provided by the hoof trimmer additional to the per herd flat rate charge and the cost of on-farm labor required during extended hoof trimmer visits), $\Sigma E V_{R}$ is the sum of the costs of on-farm recovery period labor for the hoof lesion, and $W$ is the average number of hoof trimmings per calving interval (1.6 average annual herd trimmings). Based on national data, it was assumed that $90 \%$ of hoof lesion cases were treated by the hoof trimmer, $5 \%$ were treated by the veterinarian, and the remaining $5 \%$ by the producer.

\section{RESULTS AND DISCUSSION}

\section{Prevalence and Genetic Parameters of Hoof Lesions}

The frequency of hoof lesions in the data set (Table 1) was in a very good agreement with estimates from previous studies on Canadian Holsteins (Solano et al., 2016; Malchiodi et al., 2017), with the highest prevalence for DD (16.9\%) and the lowest for TU (1.3\%). Differences in prevalence for some of the lesions compared with previous studies could also be because this data set had more data from Quebec, where there is a greater number of tiestalls compared with the national level. Cramer et al. (2008) reported the prevalence of hoof lesions to be very different among housing systems, with tiestall herds having a lower prevalence of both infectious and horn lesions compared with freestall herds.

Estimates of heritability for hoof health traits ranged from $0.03(\mathrm{SH})$ to 0.08 (DD) (Table 3). Heritabilities were generally in agreement with previous estimates for Canadian Holsteins (Malchiodi et al., 2017) and other dairy populations (van der Linde et al., 2010; Ødegård et al., 2013; Stock et al., 2017). Heringstad et al. (2018) summarized heritability estimated with linear models from different studies and found them to be generally low, ranging from 0.01 to 0.14 . Heritabilities of infectious lesions (DD, HHE, and ID) were generally higher than estimates for noninfectious lesions, similar to Dhakal et al. (2015). Higher heritability and increased accuracy of EBV were reported for DD using an alternative proposed M-scoring system (Döpfer et al., 1997; Schöpke et al., 2015). Although the higher heritability found in the study could be explained in part by the fact that data from only one herd of limited size were used (Schöpke et al., 2015), the study allowed comparisons between trait definitions. Results suggested that the M-score better represents the evolution of diseases, allowing a distinction between the susceptibility of animals to develop DD and the ability to acquire a degree

\begin{tabular}{|c|c|c|c|c|c|c|c|c|}
\hline \multirow[b]{2}{*}{ Trait } & \multicolumn{4}{|c|}{ Relative breeding value } & \multicolumn{4}{|c|}{ Reliability } \\
\hline & Mean & $\mathrm{SD}$ & Minimum & Maximum & Mean & $\mathrm{SD}$ & Minimum & Maximum \\
\hline Digital dermatitis & 100 & 5.2 & 75 & 118 & 78 & 6.5 & 70 & 99 \\
\hline Heel horn erosion & 100 & 5.0 & 77 & 122 & 77 & 6.6 & 68 & 99 \\
\hline Sole hemorrhage & 100 & 5.0 & 83 & 117 & 73 & 6.8 & 57 & 99 \\
\hline Interdigital dermatitis & 100 & 5.0 & 80 & 115 & 75 & 6.6 & 63 & 99 \\
\hline Interdigital hyperplasia & 100 & 5.3 & 66 & 117 & 75 & 6.7 & 65 & 99 \\
\hline Toe ulcer & 100 & 5.4 & 71 & 121 & 71 & 7.0 & 53 & 99 \\
\hline Sole ulcer & 100 & 5.1 & 82 & 115 & 76 & 6.6 & 65 & 99 \\
\hline White line lesion & 100 & 5.3 & 68 & 122 & 73 & 6.8 & 57 & 99 \\
\hline Hoof Health index & 100 & 5.1 & 84 & 115 & 76 & 6.6 & 66 & 99 \\
\hline
\end{tabular}

Table 2. Summary statistics for official bulls $(\mathrm{n}=2,516)^{1}$

${ }^{1}$ Official bulls based on August 2018 evaluation. 
Table 3. Estimates (posterior means) of phenotypic variance and ratios (\%) with respect to phenotypic variance for genetic $\left(h^{2}\right)$, permanent environment $\left(p e^{2}\right)$, sum of genetic and permanent environmental $\left(r^{2}\right)$, and residual $\left(e^{2}\right)$ variances (posterior SD in parentheses)

\begin{tabular}{lccccc}
\hline Hoof lesion & $\begin{array}{c}\text { Phenotypic } \\
\text { variance }\end{array}$ & $h^{2}$ & $p e^{2}$ & $r^{2}$ & $e^{2}$ \\
\hline Digital dermatitis & 0.114 & 8.36 & 12.28 & 20.64 & 79.36 \\
& $(0.0003)$ & $(0.432)$ & $(0.382)$ & $(0.234)$ & $(0.234)$ \\
Heel horn erosion & 0.018 & 7.75 & 11.18 & 18.93 & 81.07 \\
& $(0.0001)$ & $(0.454)$ & $(0.422)$ & $(0.275)$ & $(0.275)$ \\
Sole hemorrhage & 0.058 & 3.33 & 5.79 & 9.12 & 90.88 \\
& $(0.0002)$ & $(0.257)$ & $(0.250)$ & $(0.195)$ & $(0.195)$ \\
Interdigital dermatitis & 0.021 & 4.61 & 7.66 & 12.27 & 87.73 \\
Interdigital hyperplasia & $(0.0001)$ & $(0.312)$ & $(0.303)$ & $(0.219)$ & $(0.219)$ \\
& 0.019 & 6.55 & 21.68 & 28.23 & 71.77 \\
Toe ulcer & $(0.0001)$ & $(0.375)$ & $(0.347)$ & $(0.212)$ & $(0.212)$ \\
& 0.012 & 4.11 & 36.23 & 40.34 & 59.66 \\
Sole ulcer & $(<0.0001)$ & $(0.265)$ & $(0.291)$ & $(0.197)$ & $(0.197)$ \\
White line lesion & 0.070 & 5.43 & 12.24 & 17.67 & 82.33 \\
& $(0.0002)$ & $(0.346)$ & $(0.324)$ & $(0.214)$ & $(0.214)$ \\
& 0.042 & 3.71 & 12.10 & 15.81 & 84.19 \\
& $(0.0001)$ & $(0.269)$ & $(0.280)$ & $(0.199)$ & $(0.199)$ \\
\hline
\end{tabular}

of resistance after having been infected. In Canada, DD data have been recorded according to this alternative scoring since 2014 by hoof trimmers who use the latest available version of the Hoof Supervisor. Although it was not possible to use this definition in the current evaluation, the effect of the M-score on the genetic evaluation of DD will be investigated in the future.

Repeatability of hoof health traits (Table 3) ranged from $0.09(\mathrm{SH})$ to 0.40 (TU), following trends in estimates of the fraction of permanent environmental variance in the total variance. These estimates indicated a larger contribution to the phenotypic variance from nongenetic and other genetic cow factors compared with the additive genetic effects.

Generally, estimates of genetic correlations among different lesions (Table 4) were small and they varied in sign (i.e., positive and negative). Infectious (DD, HHE, and ID) and noninfectious lesions (SH, TU, SU, and WL) did not seem to be strongly genetically related, with the exception of $\mathrm{IH}$, which showed moderate correlations with DD and ID. This correlation could be explained in part by the fact that $\mathrm{IH}$ is characterized by an overgrowth of skin in the interdigital space and is often associated with chronic inflammation of the interdigital skin (common with DD infection). All infectious lesions were negatively genetically correlated with TU and WL, with the largest absolute value of correlation being between DD and WL (-0.19). Pérez-Cabal and Charfeddine (2015) reported a negative correlation of -0.30 between WL and dermatitis, which grouped digital and interdigital dermatitis. Similar correlations were reported by van der Linde et al. (2010) in the Dutch Holstein-Friesian population. Digital and interdigital dermatitis were the lesions with the strongest genetic link (genetic correlation of 0.44) in current study. Even if strong, the genetic correlation suggests that they are different traits. Digital and interdigital dermatitis are, however, often grouped together and recorded as dermatitis in a single trait. Estimates of genetic correlations were in relatively good agreement with other multiple-trait results although slightly smaller than the latest Canadian Holstein estimates (Malchiodi et al., 2017). It has to be emphasized, however, that the current study was based on a much larger data set and used a true multiple-trait model. Estimates of Malchiodi et al. (2017) were from bivariate models and had relatively higher standard errors.

\section{Trait Estimated Economic Values and Sub-Index Weights}

Estimated hoof lesion economic values and percent emphasis are presented in Table 5. Toe ulcer had the highest economic value of Can $\$ 536$ (where Can $1 \$=$ US $\$ 0.7565$; October 15, 2019) followed by DD, ID, and HHE, which had economic values of Can\$214, Can\$214, and Can $\$ 208$, respectively. Sole ulcer and WL both had a moderate economic value of Can $\$ 181$, whereas $\mathrm{IH}$ and SH had the lowest values of Can $\$ 46$ and Can $\$ 39$, respectively. The estimated values do not include the economic impact of a decrease in production, reproduction, or longevity associated with increased occurrences of hoof lesions, as these values are already considered in other index trait economic values (i.e., production traits, daughter fertility, and herd life, respectively). Calculating an economic value for animal welfare is challenging and is therefore represented through the additional labor time considered for animals still expe- 
Table 4. Estimates (posterior means) of genetic correlations (above diagonal) and permanent environmental correlations (below diagonal) with posterior standard deviations in parentheses

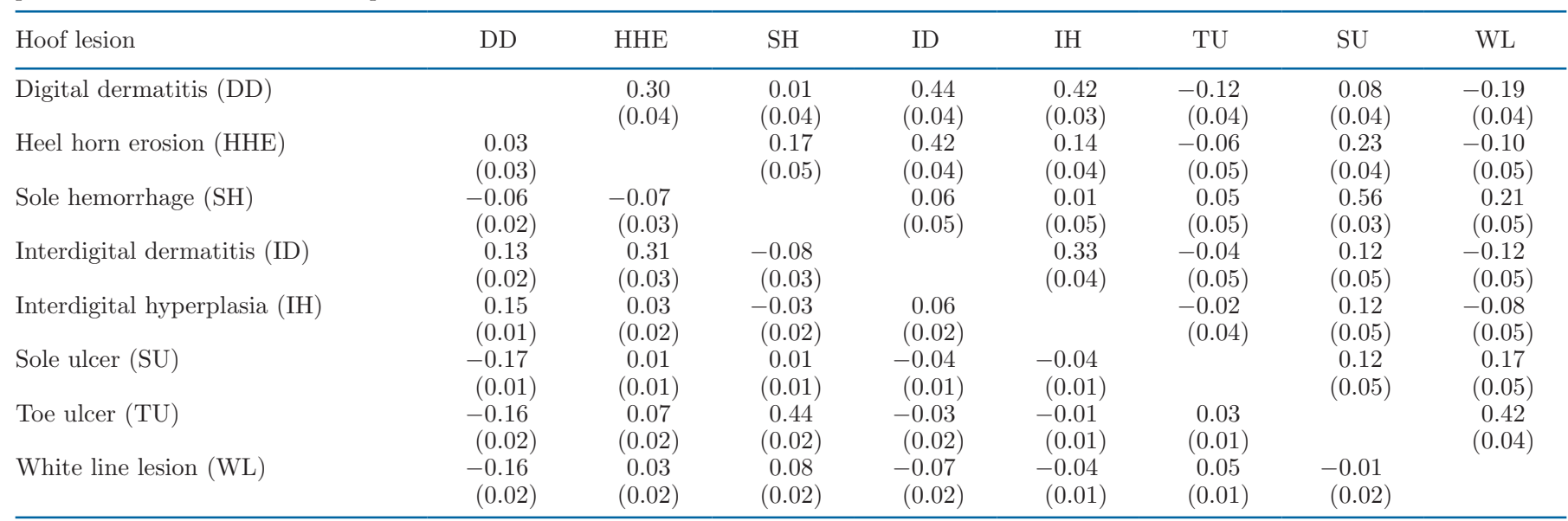

riencing lameness symptoms until fully recovered. The factors that had the greatest influence on economic values were the assigned cost of labor and the number of days for lesion recovery.

The percent emphasis was obtained by multiplying the economic value and the SD of EBV in the base population. The highest emphasis was placed on DD (34\%), followed by SU (20\%) and HHE (14\%). Moderate emphasis was given to TU (10\%), ID (9\%), and WL (8\%), and very minimal index weight emphasis was given to $\mathrm{SH}(3 \%)$ and $\mathrm{IH}(2 \%)$. Emphasis within the index therefore depends on the precision of the breeding values (which is, in turn, dependent on trait heritability and frequency of the lesion in the Canadian population). Response to selection was positive for all lesions included in the Hoof Health index, with DD having the highest response, followed by SU, HHE, and ID.

\section{Relative Breeding Values for Hoof Health}

Despite the low heritability, the distribution of the bulls' RBV showed exploitable variation among sires (Table 6). The top and bottom 10 bulls had aver-

Table 5. Lesion-specific economic values and index weight

\begin{tabular}{lcc}
\hline Hoof lesion & $\begin{array}{c}\text { Economic } \\
\text { value }^{1}(\mathrm{Can} \$)\end{array}$ & $\begin{array}{c}\text { Index } \\
\text { weight }(\%)\end{array}$ \\
\hline Digital dermatitis & 214 & 34 \\
Heel horn erosion & 208 & 14 \\
Sole hemorrhage & 39 & 3 \\
Interdigital dermatitis & 214 & 9 \\
Interdigital hyperplasia & 46 & 2 \\
Toe ulcer & 536 & 10 \\
Sole ulcer & 181 & 20 \\
White line lesion & 181 & 8 \\
\hline
\end{tabular}

${ }^{1}$ Where Can $1 \$=$ US $\$ 0.7565$; October 15, 2019. age RBV for the Hoof Health index of 113 and 85, respectively. The top 10 bulls had a higher frequency of healthy records than the bottom 10 bulls. The greatest difference was for DD, where the top 10 bulls for Hoof Health index had, on average, 95\% healthy records, whereas the bottom 10 bulls had only $64 \%$ healthy records. These results agreed with what has been experienced in other routine genetic evaluations for hoof health (e.g., from the Netherlands and the Nordic countries), which showed that breeding values with high reliabilities can be produced using data currently available, underlying how genetic selection can help to improve hoof health in dairy cattle populations in the long term (Heringstad et al., 2018).

\section{Final Remarks}

For the success of genetic evaluation, it is essential that participation in the data recording system continues over time. In addition to the genetic evaluation, an interactive report including the prevalence of lesions on farm, their trends over time, and benchmarks with provincial and national averages, was released in 2018. The report describes the events of each trimming session that occurred within 12 mo and provides 2 management lists. The first list reports all animals that have not been trimmed in a specific period ( 0 to 24 mo) and the second list shows all animals that had at least one lesion in the last 3 available trimming sessions. The benchmarks are calculated based on housing (freestall or tiestall) and milking system (pipeline, milking parlor, and robotic milking). The report is only available to producers enrolled in DHI and taking part in the data collection through their hoof trimmer. This report provides farmers with actionable data and may be perceived as an incentive to participate in the data 
Table 6. Average relative breeding values (RBV) and proportion of healthy records for top 10 and bottom 10 official bulls ${ }^{1}$ by Hoof Health index (SD in parentheses)

\begin{tabular}{lccccc}
\hline & \multicolumn{2}{c}{ RBV } & & \multicolumn{2}{c}{ Healthy records (\%) } \\
\cline { 2 - 3 } \cline { 5 - 6 } Hoof lesion & Top 10 & Bottom 10 & & Top 10 & Bottom 10 \\
\hline Digital dermatitis & $111(2.9)$ & $85(5.3)$ & & $95(5.5)$ & $64(16.6)$ \\
Heel horn erosion & $111(5.1)$ & $93(2.5)$ & & $97(3.9)$ & $96(5.7)$ \\
Sole hemorrhage & $109(5.6)$ & $94(3.9)$ & & $96(6.3)$ & $90(8.8)$ \\
Interdigital dermatitis & $110(3.4)$ & $90(3.7)$ & & $99(1.3)$ & $94(4.9)$ \\
Interdigital hyperplasia & $106(4.7)$ & $87(9.4)$ & & $100(0.0)$ & $88(23.8)$ \\
Toe ulcer & $100(5.1)$ & $97(10.4)$ & & $99(2.8)$ & $94(8.0)$ \\
Sole ulcer & $109(2.6)$ & $91(3.3)$ & & $98(3.8)$ & $83(7.5)$ \\
White line lesion & $102(4.2)$ & $98(5.5)$ & & $98(4.4)$ & $93(3.4)$ \\
Hoof Health index & $113(0.9)$ & $85(1.0)$ & & & \\
\hline
\end{tabular}

${ }^{1}$ Official bulls based on August 2018 evaluation.

collection. Because participation of hoof trimmers in the data collection is limited, alternative options for collection of the hoof health data are being explored. Finally, correlations between RBV for hoof health and traits currently under selection in Canada were all favorable, suggesting that selecting for hoof health would not negatively affect the selection of other economically important traits.

\section{CONCLUSIONS}

Data recorded by hoof trimmers through a centralized data collection system were used to develop a genomic evaluation for hoof health. The new Hoof Health index was built using economic weights for hoof lesions based on the Canadian dairy system. Despite the low heritability, exploitable genetic variation for most hoof lesions was found in the Canadian Holstein population, suggesting that genetic selection would be effective for enhancing resistance to hoof lesions in the long term. Within this data collection system, an interactive management report was also created. This management tool will help producers monitor the incidence of lesions at the farm level, identify best management practices, and evaluate treatments, thus helping to reduce the incidence of hoof lesions in the Canadian dairy cattle population.

\section{ACKNOWLEDGMENTS}

The authors are grateful to the hoof trimmers who participated in this study. This research was supported by a contribution from the Dairy Research Cluster Initiative [Dairy Farmers of Canada (Ottawa, ON, Canada), Agriculture and Agri-Food Canada (Ottawa, ON, Canada), the Canadian Dairy Network (Guelph, ON, Canada), and the Canadian Dairy Commission (Ottawa, ON, Canada)], Ontario Genomics (Toronto, ON,
Canada), and Alberta Milk (Edmonton, AB, Canada). The authors have not stated any conflicts of interest.

\section{REFERENCES}

Alberta dairy hoof health project. 2014. The Alberta dairy hoof health project: Lesion severity scoring guide. http://dairyhoofhealth .info/Lesion-Severity- Guide-v0.7.pdf.

Berry, D., and P. Amer. 2005. Derivation of a health sub-index for the Economic Breeding Index in Ireland. Moorepark Production Research Centre Extension, Cork, Ireland.

Buch, L. H., A. C. Sørensen, J. Lassen, P. Berg, J. A. Eriksson, J. H. Jakobsen, and M. K. Sørensen. 2011. Hygiene-related and feedrelated hoof diseases show different patterns of genetic correlations to clinical mastitis and female fertility. J. Dairy Sci. 94:1540-1551. https://doi.org/10.3168/jds.2010-3137.

Chapinal, N., A. Koeck, A. Sewalem, D. F. Kelton, S. Mason, G. Cramer, and F. Miglior. 2013. Genetic parameters for hoof lesions and their relationship with feet and leg traits in Canadian Holstein cows. J. Dairy Sci. 96:2596-2604. https://doi.org/10.3168/jds.2012 $-6071$.

Cramer, G., K. D. Lissemore, C. L. Guard, K. E. Leslie, and D. F. Kelton. 2008. Herd- and cow-level prevalence of foot lesions in Ontario dairy cattle. J. Dairy Sci. 91:3888-3895. https://doi.org/ $10.3168 /$ jds. $2008-1135$.

Dhakal, K., F. Tiezzi, J. S. Clay, and C. Maltecca. 2015. Short communication: Genomic selection for hoof lesions in first-parity US Holsteins. J. Dairy Sci. 98:3502-3507. https://doi.org/10.3168/jds .2014-8830.

Döpfer, D., A. A. H. M. ter Huurne, J. L. Cornelisse, A. J. A. M. van Asten, A. Koopmans, F. A. Meijer, Y. H. Schukken, I. Szakall, W. Klee, and R. B. Bosma. 1997. Histological and bacteriological evaluation of digital dermatitis in cattle, with special reference to spirochaetes and Campylobacter faecalis. Vet. Rec. 140:620-623. https://doi.org/10.1136/vr.140.24.620.

Egger-Danner, C., P. Nielsen, A. Fiedler, A. Müller, T. Fjeldaas, D. Döpfer, V. Daniel, C. Bergsten, G. Cramer, A.-M. Christen, K. F. Stock, G. Thomas, M. Holzhauer, A. Steiner, J. Clarke, N. Capion, N. Charfeddine, J. E. Pryce, E. Oakes, J. Burgstaller, B. Heringstad, C. Ødegård, J. Kofler, F. Egger, and J. B. Cole. 2015. ICAR Claw Health Atlas. ICAR Technical Series. No. 18. International Committee for Animal Recording, Rome, Italy.

Guard, C. 2017. Lameness Reduces Overall Herd Performance. Cornell Extension, Ithaca, NY.

Heringstad, B., C. Egger-Danner, N. Charfeddine, J. E. Pryce, K. F. Stock, J. Kofler, A. M. Sogstad, M. Holzhauer, A. Fiedler, K. Müller, P. Nielsen, G. Thomas, N. Gengler, G. de Jong, C. Ødegård, F. Malchiodi, F. Miglior, M. Alsaaod, and J. B. Cole. 2018. Invited review: Genetics and claw health: Opportunities to enhance claw 
health by genetic selection. J. Dairy Sci. 101:4801-4821. https:// doi.org/10.3168/jds.2017-13531.

Jamrozik, J., A. Koeck, G. J. Kistemaker, and F. Miglior. 2016. Multiple-trait estimates of genetic parameters for metabolic disease traits, fertility disorders, and their predictors in Canadian Holsteins. J. Dairy Sci. 99:1990-1998. https://doi.org/10.3168/jds .2015-10505.

Koeck, A., J. Jamrozik, G. J. Kistemaker, F. S. Schenkel, R. K. Moore, D. M. Lefebvre, D. F. Kelton, and F. Miglior. 2015. Development of genetic evaluations for metabolic disease traits for Canadian dairy cattle. Interbull Bull. 49:76-79.

Malchiodi, F., J. Jamrozik, A.-M. Christen, G. J. Kistemaker, P. G. Sullivan, B. J. Van Doormaal, D. F. Kelton, F. S. Schenkel, and F. Miglior. 2018. Implementation of genomic evaluation for digital dermatitis in Canada. Interbull Bull. 53:71-75.

Malchiodi, F., A. Koeck, S. Mason, A.-M. Christen, D. F. Kelton, F. S. Schenkel, and F. Miglior. 2017. Genetic parameters for hoof health traits estimated with linear and threshold models using alternative cohorts. J. Dairy Sci. 100:2828-2836. https://doi.org/10.3168/jds 2016-11558.

Manske, T., J. Hultgren, and C. Bergsten. 2002. Prevalence and interrelationships of hoof lesions and lameness in Swedish dairy cows. Prev. Vet. Med. 54:247-263. https://doi.org/10.1016/S0167 -5877(02)00018-1.

Miglior, F., A. Fleming, F. Malchiodi, L. F. Brito, P. Martin, and C. F. Baes. 2017. A 100-Year Review: Identification and genetic selection of economically important traits in dairy cattle. J. Dairy Sci. 100:10251-10271.

MiX99 Development Team. 2017. MiX99: A software package for solving large mixed model equations. Release XI/2017. Natural Resources Institute Finland (Luke), Jokioinen, Finland. http://www luke.fi/mix99.

Ødegård, C., M. Svendsen, and B. Heringstad. 2013. Genetic analyses of claw health in Norwegian Red cows. J. Dairy Sci. 96:7274-7283.

Ødegård, C., M. Svendsen, and B. Heringstad. 2014. Genetic correlations between claw health and feet and leg conformation in Norwegian Red cows. J. Dairy Sci. 97:4522-4529. https://doi.org/10 .3168/jds.2013-7837.
Pérez-Cabal, M. A., and N. Charfeddine. 2015. Models for genetic evaluations of claw health traits in Spanish dairy cattle. J. Dairy Sci. 98:8186-8194. https://doi.org/10.3168/jds.2015-9562.

Sargolzaei, M., J. P. Chesnais, and F. S. Schenkel. 2014. A new approach for efficient genotype imputation using information from relatives. BMC Genomics 15:478. https://doi.org/10.1186/1471 -2164-15-478.

Schöpke, K., A. Gomez, K. A. Dunbar, H. H. Swalve, and D. Döpfer. 2015. Investigating the genetic background of bovine digital dermatitis using improved definitions of clinical status. J. Dairy Sci. 98:8164-8174. https://doi.org/10.3168/jds.2015-9485.

Shearer, J. K., and S. R. van Amstel. 2011. Lameness in dairy cattle. Pages 233-253 in Dairy Production Medicine. 1st ed. John Wiley \& Sons Inc., Chichester, West Sussex, UK.

Solano, L., H. W. Barkema, S. Mason, E. A. Pajor, S. J. LeBlanc, and K. Orsel. 2016. Prevalence and distribution of foot lesions in dairy cattle in Alberta, Canada. J. Dairy Sci. 99:6828-6841. https://doi .org/10.3168/jds.2016-10941.

Stock, K. F., H. H. Swalve, R. Schafberg, V. Muller-Ratz, and F. Reinhardt. 2017. Genetic evaluation for claw health traits as part of the integrated system for health monitoring in German Holstein dairy cattle. ICAR Tech. Ser. 22:55-60.

van der Linde, C., G. de Jong, E. P. C. Koenen, and H. Eding. 2010. Claw health index for Dutch dairy cattle based on claw trimming and conformation data. J. Dairy Sci. 93:4883-4891. https://doi .org/10.3168/jds.2010-3183.

\section{ORCIDS}

F. Malchiodi 우 https://orcid.org/0000-0002-1151-0845

J. Jamrozik () https://orcid.org/0000-0002-6953-6706

A. Fleming $\odot$ https://orcid.org/0000-0003-4706-7846

D. F. Kelton (ㄴ) https://orcid.org/0000-0001-9606-7602

F. S. Schenkel $\odot$ https://orcid.org/0000-0001-8700-0633

F. Miglior () https://orcid.org/0000-0003-2345-8842 